\title{
RESPONS PESERTA PELATIHAN URBAN FARMING YANG RAMAH LINGKUNGAN SECARA ONLINE
}

\author{
Fiky Yulianto Wicaksono, dan Tati Nurmala \\ Prodi Agroteknologi, Fakultas Pertanian, Universitas Padjadjaran \\ E-mail: fiky.yulianto@unpad.ac.id
}

\begin{abstract}
ABSTRAK. Hobi urban farming semakin meningkat pada saat pandemi Covid-19 ini, terutama saat Pembatasan Sosial Berskala Besar dan Pemberlakuan Pembatasan Kegiatan Masyarakat yang mengharuskan masyarakat tinggal di rumah. Kegiatan urban farming yang dilakukan banyak terkait dengan teknik hidroponik yang membutuhkan biaya besar, pengetahuan yang baik, serta limbah yang tidak tertangani sehingga membutuhkan teknik alternatif untuk mengatasi permasalahan tersebut dan harus disosialisasikan pada masyarakat. Tujuan sosialisasi ini adalah untuk mengenalkan urban farming yang ramah lingkungan pada masyarakat dengan memanfaatkan limbah rumah tangga. Metode yang digunakan berupa pelatihan dan simulasi mengenai urban farming yang ramah lingkungan yang dilaksanakan secara online dari bulan Januari - Februari 2021. Pelatihan dilakukan oleh narasumber yang ahli dalam urban farming. Simulasi dilakukan dengan cara demonstrasi dalam bentuk video. Peserta kegiatan diseleksi dengan kriteria telah atau ingin mempraktekkan urban farming di rumah atau sekitar rumah dan bersedia untuk mengikuti pelatihan. Hasil sosialisasi menunjukkan keahlian narasumber dapat meningkatkan wawasan peserta. Sebagian besar peserta memahami materi pelatihan dan mempraktekkan urban farming yang ramah lingkungan di rumah atau sekitar rumah.
\end{abstract}

Kata kunci: Kompos; Limbah; Ramah lingkungan; Urban farming

ABSTRACT. The hobby of urban farming has increased during the Covid-19 pandemic, especially during social and physical distancing which require people to stay at home. Urban farming are carried out in many ways related to hydroponic techniques which require large costs, good knowledge, and untreated waste so that they require alternative techniques to solve these problems and must be socialized to the community. The purpose of this socialization is to introduce eco-friendly urban farming to the community by utilizing household waste. The method used training and simulations on eco-friendly urban farming which was conducted online from January to February 2021. The training was conducted by experts in urban agriculture. The simulation was carried out by demonstrating in videos. Participants have been selected that had or want to practice urban farming at home or around the house and were willing to take part in the training. The results of the socialization showed that the expertise of experts can increase participants knowledge. Most of the participants understood the training materials and practiced eco-friendly urban agriculture at home or around the house.

Keywords: Compost; Eco-friendly; Urban Farming; Waste

\section{PENDAHULUAN}

Pandemi Covid-19 yang masuk ke Indonesia pada awal tahun 2020 menyebabkan masyarakat membatasi kegiatannya agar tidak tertular penyakit tersebut. Pemerintah juga mengeluarkan peraturan berupa Pembatasan Sosial Berskala Besar (PSBB), kemudian disusul dengan Pemberlakuan Pembatasan Kegiatan Masyarakat (PPKM) yang mengimbau masyarakat agar membatasi physical and social distancinguntukmemutus rantai penyebaran penyakit tersebut. Sebagian masyarakat kemudian menjalani pekerjaannya di rumah (Work from Home, $\mathrm{WFH}$ ) dan juga belajar dari rumah (BDR). Masyarakat dalam melakukan WFH dan BDR seringkali merasakan stress dan jenuh (Lestyoningsih, 2020; Deliviana et al., 2020). Salah satu hobi untuk mengurangi kejenuhan tersebut adalah dengan berkebun atau urban farming (Amalia dan Somad, 2020).

Urban farming merupakan kegiatan bercocok tanam yang dilakukan di perkotaan dimana sedikit sekali bahkan tidak ada lahan pertanian. Kegiatan bercocok tanam ini memanfaatkan lahan-lahan tidur yang tidak terpakai, halaman rumah, bahkan atap rumah (Sihgiyanti, 2016; Iftisan, 2013). Masyarakat dapat mengambil manfaat dari kegiatan urban farming ini, seperti peningkatan pendapatan masyarakat dan mengurangi biaya hidup di perkotaan (Iftisan, 2013). Sebagian besar masyarakat yang melakukan urban farming saat ini lebih menyukai bercocok tanam menggunakan teknik hidroponik (Mindari, 2019). Hidroponik merupakan teknik bercocok tanam tanpa menggunakan media tanam tanah dengan memfokuskan pada penggunaan larutan nutrisi. Kelebihan hidroponik adalah pertumbuhan tanaman lebih seragam, lebih bersih, dan menghemat ruang (Wachdijono et al., 2019). Teknik hidroponik di sisi lain memiliki kelemahan, diantaranya adalah biaya relatif mahal, memerlukan pemahaman nutrisi tanaman yang baik, serta limbah hasil pertanian yang tidak tertangani (Roidah, 2014). Solusi untuk menangani kelemahan tersebut adalah dengan melakukan urban farming yang ramah ling-kungan dengan memanfaatkan limbah dari rumah tangga dan lingkungan sekitar, baik untuk input nutrisi, media tanam, bahkan dimanfaatkan untuk instalasi penanaman. 
Sosialisasi urban farming yang ramah lingkungan perlu dilakukan, terutama ketika hobi urban farming terus berkembang pada saat pandemi ini. Pelatihan urban farming yang ramah lingkungan pada masyarakat diharapkan selain dapat mengurangi biaya hidup di perkotaan juga dapat mengurangi limbah di masyarakat sehingga tercipta lingkungan yang lebih bersih dan lebih nyaman. Para pemuda dan ibu-ibu rumah tangga yang mempunyai hobi urban farming diajak turut serta dalam kampanye urban farming yang ramah lingkungan ini sebab mereka merupakan agen perubahan dalam perkembangan masyarakat (Suradi, 2019; Fadhlillah et al., 2020).

\section{METODE}

Sosialisasi dan pelatihan urban farming yang ramah lingkungan dilakukan secara online. Hal ini disebabkan pandemi Covid-19 belum berakhir sehingga kegiatan harus dapat memfasilitasi peraturan PSBB ataupun PPKM. Sosialisasi dilakukan dari mulai bulan Januari sampai dengan Februari 2021. Peserta kegiatan ini berjumlah 53 orang, yang sebagian besar adalah para pemuda dan ibu rumah tangga yang berdomisili di Jawa Barat (Ciamis, Majalengka, Sumedang, Bandung, Tasikmalaya, Banjar, Depok, Garut, Bekasi, Ciamis, dan Bogor), DKI Jakarta (Jakarta Timur dan Jakarta Barat), Jawa Tengah (Purwokerto), dan Sumatera Utara (Medan dan Simalungun). Peserta kegiatan telah dijaring oleh mahasiswa Universitas Padjadjaran yang sedang mengikuti Kuliah Kerja Nyata Mahasiswa (KKNM) di bulan Januari-Februari 2021 dengan kriteria telah atau ingin mempraktekkan urban farming di rumah atau sekitar rumah dan bersedia untuk mengikuti sosialisasi dan pelatihan mengenai urban farming yang ramah lingkungan.

Metode yang digunakan dalam kegiatan ini adalah pelatihan dan simulasi IPTEKS. Metode pelatihan terdiri dari penyampaian materi mengenai urban farming dari narasumber (dosen UNPAD yang merupakan pakar di bidang urban farming) serta diskusimengenai materiyang disampaikan. Sebagian topik materi yang akan disampaikan merupakan permintaan dari peserta berdasarkan kebutuhan pengetahuan mereka untuk mempraktekkan urban farming yang ramah lingkungan. Materi urban farming yang ramah lingkungan terdiri dari cara pembuatan nutrisi alami dari pengomposan limbah organik rumah tangga, pemanfaatan limbah rumah tangga sebagai instalasi penanaman tanaman, teknologi budidaya tanaman di lahan sempit, kemudian cara panen dan pascapanen yang benar. Simulasi IPTEKS berupa demonstrasi pembuatan kompos dari limbah organik rumah tangga dalam wadah yang kecil (karung dan sejenisnya), pembuatan pot-pot bekas dari limbah plastik (botol air mineral, plastik kemasan minyak goreng, ember cat, dan sebagainya), serta pemeliharaan tanaman dan penanganan pascapanennya. Simulasi IPTEKS dilakukan oleh mahasiswa KKNM kemudian videonya dibagikan secara online.

Evaluasi setelah sosialisasi dan pelatihan dilakukan untuk menilai sejauhmana materi pelatihan dapat dipahami oleh peserta kegiatan, setelah mengikuti materi apakah tertarik untuk mempraktekkan urban farming yang ramah lingkungan, apa yang diharapkan kelak dari praktek budidaya urban farming yang ramah lingkungan ini, apakah peserta bersedia untuk membagikan pengetahuan dalam pelatihan ke orang lain. Evaluasi dilakukan dengan cara menyebar kuesioner pada peserta. Hasil evaluasi disajikan secara deskriptif.

\section{HASIL DAN PEMBAHASAN}

\section{Kelayakan peserta}

Penjaringan mahasiswa terhadap masyarakat yang dijadikan peserta memiliki latar belakang umur, pendidikan, pekerjaan, serta jumlah anggota keluarga di rumah yang beragam. Rata-rata umur peserta yang telah diseleksi adalah 24,8 tahun dengan rentang antara $18-58$ tahun. Pendidikan terakhir mayoritas peserta adalah SMA (55\%), rentang beragam dari SD sampai dengan SMA. Pekerjaan sebagian besar peserta adalah mahasiswa sebanyak 56\%. Rata-rata jumlah anggota keluarga di rumah yang ditempati peserta adalah 4,3 orang (Gambar 1). Umur peserta yang masih muda sangat cocok sebagai agen perubahan dan agen pengembangan di masyarakat (Hanafie dan Ahmad, 2019; Mayasari dan Husin, 2014). Pendidikan peserta yang sebagian besar telah lulus dari SMA dianggap dapat memahami materi pelatihan yang akan diberikan karena kurikulum yang dikembangkan di SMA memungkin lulusan SMA dapat berpikir kritis (Susilawati et al., 2020). Pekerjaan peserta yang mayoritas adalah mahasiswa memberikan potensi waktu luang lebih banyak dan dapat digunakan untuk mengembangkan kreativitas (Utami, 2009). Jumlah anggota keluarga lebih dari satu orang, sehingga peserta berpotensi untuk mengenalkan materi pelatihan pada orang terdekatnya. Oleh karena itu, latar belakang peserta dinilai layak untuk mempraktekkan dan mengembangkan urban farming yang ramah lingkungan serta mengenalkan pada orang lain.

Peserta juga dinyatakan layak karena semua menyatakanbersediamenerimapelatihandansebagian besar pernah membudidayakan tanaman di rumah. Sebanyak 94\% peserta pernah membudidayakan tanaman di rumah dan $98 \%$ mengetahui manfaat dari urban farming. Pengalaman dan pengetahuan awal 
dalam mempraktekkan budidaya tanaman menjadi penting karena peserta menjadi responsif terhadap hal-hal baru sehingga alih pengetahuan akan lebih mudah (Sadono, 2008). Semua peserta mempunyai minat untuk mempraktekkan urban farming yang ramah lingkungan di rumah dan sekitar rumahnya. Minat untuk mengembangkan wawasan dengan cara mempraktekkan merupakan hal penting untuk mengembangkan diri (Bunch, 2001).

\section{Pemberian materi pelatihan}

Penyampaian materi oleh narasumber mendapat apresiasi dari peserta pelatihan. Rata-rata peserta memberikan nilai 4,4 dari skala skor 1 (sangat kurang) sampai dengan 5 (sangat baik) untuk penilaian kemampuan dan wawasan narasumber dalam memberikan materi. Peserta juga melakukan penilaian sendiri terhadap pemahaman pada materi dengan ratarata nilai 4,1 dari skala skor 1 (sangat kurang) sampai dengan 5 (sangat baik). Sebanyak 85\% materi dari narasumber merupakan wawasan baru yang diterima oleh peserta. Peserta tertarik untuk melakukan urban farming yang ramah lingkungan dengan rata-rata skor 4,4 dari skala 1 sampai dengan 5 (Gambar 2). Sebanyak $92 \%$ peserta juga ingin menyampaikan wawasan setelah mengikuti pelatihan pada orangorang di sekitarnya. Hal ini menunjukkan bahwa narasumber yang berwawasan luas dapat menentukan keberhasilan alih pengetahuan dari suatu pelatihan juga dapat menarik minat peserta untuk melakukan urban farming (Rochmawati et al., 2019).

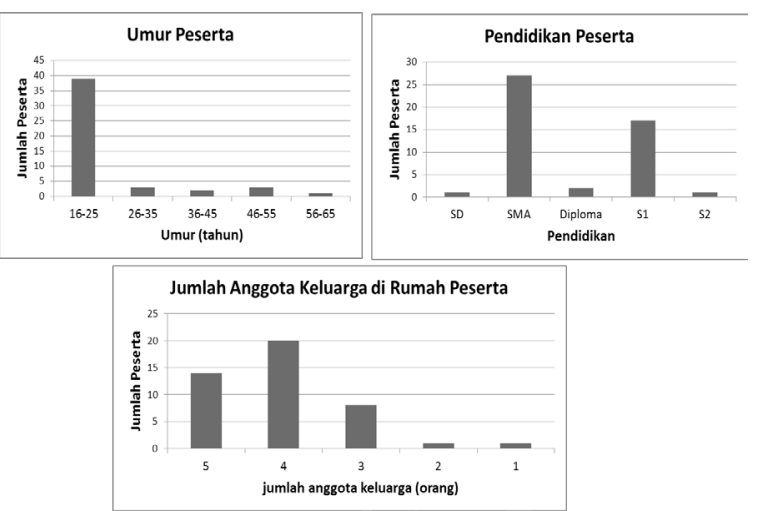

Gambar 1. Profil peserta pelatihan dan simulasi
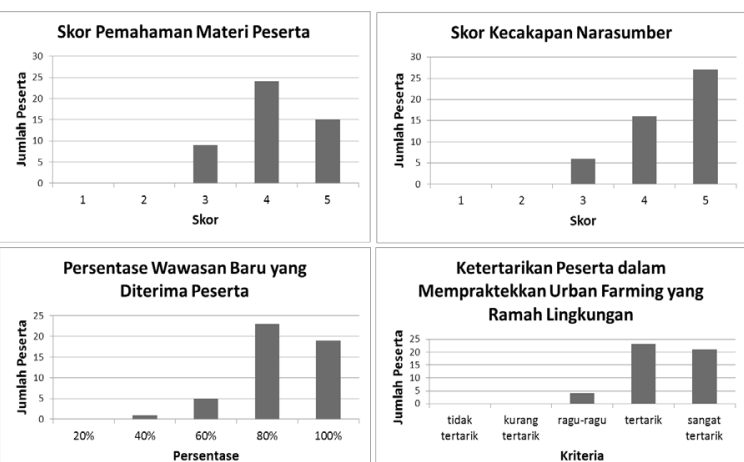

Demonstrasi urban farming yang ramah lingkungan dalam bentuk video yang dilakukan oleh mahasiswa KKNM juga mendapatkan apresiasi dari peserta pelatihan. Peserta tertarik untuk mempraktekkan cara-cara urban farming yang ramah lingkungan yang telah dipraktekkan oleh mahasiswa KKNM, diantaranya adalah pembuatan kompos dari sampah organik dan pemanfaatan barang bekas untuk pengganti pot. Sebanyak $77,5 \%$ peserta tertarik untuk membuat kompos dari sampah organik seperti yang dilakukan oleh mahasiswa KKNM, sementara $87 \%$ tertarik untuk memanfaatkan barang bekas sebagai pengganti pot. Hal ini membuktikan bahwa demonstrasi atau simulasi merupakan salah satu metode yang mendukung keberhasilan pelatihan. Metode penyuluhan yang tepat menjadi faktor yang mempengaruhi adopsi suatu inovasi (Wicaksono et al., 2018).

\section{Kegiatan setelah pelatihan}

Peserta diberikesempatanuntuk mencobaurban farming yang ramah lingkungan setelah pelatihan. Sebagian besar mempraktekkan urban farming yang ramah lingkungan dengan motivasi ingin mengurangi biaya rumah tangga, mudah mendapatkan kebutuhan pangan sehari-hari, melestarikan lingkungan, lebih sehat, meningkatkan pendapatan, mengisi waktu luang, dan lain-lain (Tabel 1). Motivasi dibutuhkan bagi peserta untuk dapat mempraktekkan urban farming yang ramah lingkungan, seperti diutarakan oleh Bunch (2001) bahwa keberhasilan pelatihan bergantung pada kebutuhan yang benar-benar dirasakan oleh pesertanya.

Tabel 1. Motivasi peserta untuk mempraktekkan urban farming yang ramah lingkungan

\begin{tabular}{lc}
\hline \multicolumn{1}{c}{ Motivasi peserta } & Jumlah peserta \\
\hline Mengurangi biaya rumah tangga & 3 \\
$\begin{array}{l}\text { Mudah mendapatkan kebutuhan pangan } \\
\text { sehari-hari }\end{array}$ & 7 \\
Melestarikan lingkungan di sekitar rumah & 19 \\
Lebih sehat & 2 \\
Meningkatkan pendapatan & 3 \\
Mengisi waktu luang & 5 \\
Lain-lain & 9 \\
\hline
\end{tabular}

Peserta melakukan urban farming di berbagai tempat, seperti pekarangan, lingkungan sekitar rumah, atap rumah (rooftop), dan lain-lain. Pembuatan kompos dilakukan di karung, ember, drum, ember bekas cat, dan lain-lain. Tanaman ditanam dalam botol air mineral, kaleng, ember bekas, paralon, plastik kemasan minyak, dan lain-lain (Gambar 3).

Gambar 2. Evaluasi saat pemberian pelatihan 


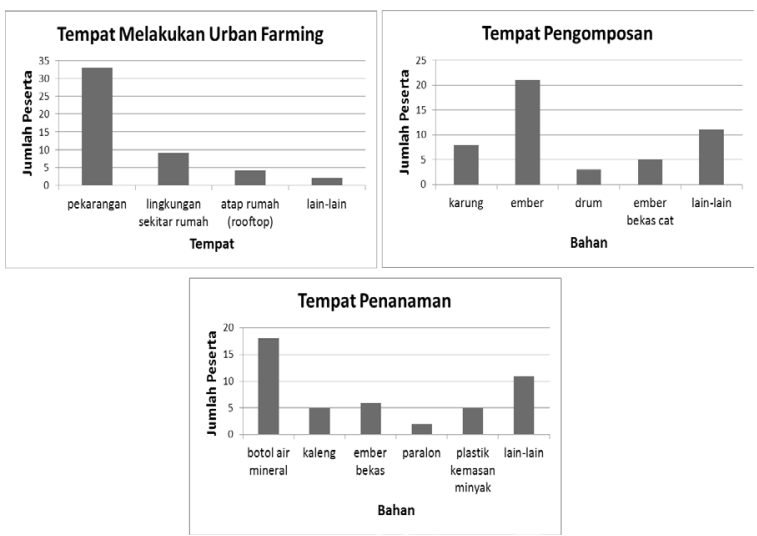

Gambar 3. Preferensi peserta untuk memilih lokasi urban farming, tempat pengomposan, dan tempat penanaman

Beberapa kendala yang dirasakan oleh peserta diantaranya adalah kepraktisan dan waktu pembuatan kompos terlalu lama, kurangnya waktu untuk mengurus tanaman, serta adanya hama dan penyakit tanaman. Adanya kendala ini diharapkan dapat tertutup oleh motivasi yang kuat dari para peserta seperti telah dijelaskan sebelumnya. Hal ini juga sesuai dengan pendapat As'ad et al. (2019) bahwa motivasi yang kuat dapat mengalahkan kendala yang dihadapi.

\section{SIMPULAN}

Pelatihan urban farming yang ramah lingkungan secara online mendapatkan respons dari masyarakat dengan mempraktekkan di lingkungan rumahnya.

\section{UCAPAN TERIMAKASIH}

Ucapan terimakasih ditujukan pada mahasiswa KKNM bulan Januari - Februari 2021 dengan topik "Urban Farming yang Ramah Lingkungan"

\section{DAFTAR PUSTAKA}

Amalia, A. F., \& Somad, A. 2020. Study on the Impact of Family-based Food Security Program during the Coronavirus Pandemic. Proceeding The 3rd International Seminar on Family and Consumer Issues in Asia Pacific, 63-68. Bogor: IPB University.

As'ad, A., Syahnur, H., \& Arumbarkah, M. 2019. Pelatihan Motivasi dan Kewirausahaan Bagi Warga Desa. Jurnal Pengabdian Bina Ukhuwah, 1(2), 8-15.

Bunch, R. 2001. Dua Tongkol Jagung: Pedoman Pengembangan Pertanian Berpangkal pada Rakyat. Jakarta: Yayasan Obor Indonesia.

Deliviana, E., Erni, M. H., Hilery, P. M., \& Naomi, N. M. 2020. Pengelolaan kesehatan mental mahasiswa bagi optimalisasi pembelajaran online di masa pandemi covid-19. Jurnal Selaras, 3(2), 129-138. https://doi.org/https:// doi.org/10.33541/Jsvol2iss1pp1

Fadhlillah, A. N., Santoso, M. B., \& Zainuddin, M. 2020. Empowering the Smart Mothers Sebagai Upaya Pemberdayaan Ibu Rumah Tangga Dalam Mengelola Sampah. Prosiding Penelitian Dan Pengabdian Kepada Masyarakat, 7(1), 149. https://doi. org/10.24198/jppm.v7i1.27120

Hanafie, N. K., \& Ahmad, M. R. S. 2019. Remaja sebagai agen pengembangan masyarakat pedesaan di Kelurahan Paccinongang Kabupaten Gowa. Seminar Nasional Hasil Pengabdian Kepada Masyarakat, Universitas Negeri Makassar, 333-335.

Iftisan, M. 2013. Penerapan Program Urban Farming di RW 04 Tamansari Bandung. Reka Loka, 1(1), 1-11.

Lestyoningsih, I. H. 2020. Literatur review: implementasi responsif gender dimasa pandemi Covid 19. Seminar Nasional Kesehatan Masyarakat, 68-83. UPN Veteran Jakarta.

Mayasari, S., \& Husin, A. 2014. Remaja genre: peluang menuju bonus demografi. Demography Journal of Sriwijaya, 1(2), 4-8.

Mindari, W. 2019. Urban farming kelompok wanita tani flamboyan berbasis hidroponik dan vertikultur. Prosiding Seminar Nasional Hasil Pengabdian Masyarakat, 3(1), 182-187.

Rochmawati, U., Timan, A., \& Kusumaningrum, D. E. 2019. Manajemen pendidikan dan pelatihan keahlian ganda guru sekolah menengah kejuruan. Jurnal Administrasi Dan Manajemen Pendidikan, 2(3), 147-155.

Roidah, I. S. (2014). Pemanfaatan lahan dengan menggunakan sistem hidroponik. Jurnal Bonorowo, 1(2), 43-49. https://doi.org/https:// doi.org/10.36563/bonorowo.v1i2.14

Sadono, D. 2008. Pemberdayaan Petani: Paradigma Baru Penyuluhan Pertanian di Indonesia. Jurnal Penyuluhan, 4(1), 65-74. https://doi.org/https:// doi.org/10.25015/penyuluhan.v4i1.2170

Sihgiyanti;, V. J. 2016. Evaluasi Implementasi Program Urban Farming Oleh Dinas Pertanian Di Kota Surabaya. Kebijakan Dan Manajemen Publik, 4(2), 264-272.

Suradi, S. 2019. Karang taruna, agen perubahan dan pengembangan masyarakat di pandeglang. Sosio Konsepsia, 8(3), 241-254. https://doi. org/10.33007/ska.v8i3.1676 
Susilawati, E., Agustinasari, Samsudin, A., \& Siahaan, P. 2020. Analisis Tingkat Keterampilan Berpikir Kritis Siswa SMA. Jurnal Pendidikan Fisika Dan Teknologi, 6(1), 11-16. https://doi.org/http://dx.doi. org/10.29303/jpft.v6i1.1453

Utami, M. S. 2009. Keterlibatan dalam Kegiatan dan Kesejahteraan Subjektif Mahasiswa. Jurnal Psikologi, 36(2), 144-163. https://doi. org/10.22146/jpsi.7892

Wachdijono, W., Wahyuni, S., \& Trisnaningsih, U. 2019. Sosialisasi Urban Farming Melalui Budidaya Tanaman Sayuran Secara
Vertikultur Dan Hidroponik Di Kelurahan Kalijaga, Kecamatan Harjamukti, Kota Cirebon. Qardhul Hasan: Media Pengabdian Kepada Masyarakat, 5(2), 90. https://doi. org/10.30997/qh.v5i2.1928

Wicaksono, F. Y., Maxiselly, Y., Nurmala, T., Suherman, P. U., Fauzan, A., \& Nurdin, A. M. 2018. Respons masyarakat terhadap pengenalan tanaman gandum dan produkproduknya di Desa Arjasari Kecamatan Arjasari Kabupaten Bandung. Dharmakarya, 7(1), 32-37. https://doi.org/https://doi. org/10.24198/dharmakarya.v7i1.14740 